\title{
Proteins Rapidly Transported to the Synapses of a Single Identified Neuron of Aplysia californica ${ }^{1}$
}

\author{
RICHARD T. AMBRON, ${ }^{2}$ SAMUEL SCHACHER, AND STEPHEN G. RAYPORT \\ Departments of Anatomy and Cell Biology, and Psychiatry, Center for Neurobiology and Behavior, College of Physicians and Surgeons, \\ Columbia University and The New York State Psychiatric Institute, New York, New York 10032
}

\begin{abstract}
The cell body of R2, a giant cholinergic neuron of Aplysia californica, resides in the abdominal ganglion, whereas its synapses are on thousands of unicellular mucus glands located in the skin. Due to the great spatial separation between the site of macromolecular synthesis and the presynaptic terminals, rapid axonal transport can be used to segregate synaptic proteins from those to be used elsewhere in the cell. The proteins of R2 were labeled by incubating the abdominal ganglion in $\left.{ }^{35} \mathrm{~S}\right]$ methionine for $5 \mathrm{hr}$ in a chamber separated from the rest of the isolated central nervous system. After $\mathbf{5 0}$ hr, 28 radiolabeled proteins were reproducibly found by one- and two-dimensional polyacrylamide gel electrophoresis to be transported to the distal regions of peripheral nerves $P_{6}, P_{7}$, and $P_{8}$ that innervate the parapodia and middle body wall. We are sure that R2 is the source of these proteins since radioautography of sections taken throughout the nervous system, complemented by cobalt tracings, showed that $R 2$ is the only neuron in the abdominal ganglion with axons in these nerves. Nine of the 28 transported proteins are glycoproteins since they were also labeled after injecting R2's cell body with [ $\left.{ }^{3} \mathrm{H}\right]$-L-fucose.

There is evidence that the proteins and glycoproteins are destined for R2's presynaptic terminals. For example, in experiments in which the body wall and parapodium remained attached to the nerves, the proteins were transported to the skin region that contains the glands. Moreover, analyses of the distribution of the rapidly transported proteins by qualitative radioautography and by extrusion of axoplasm indicated that none are constituents of the axolemma. Having identified a group of components that presumably function at R2's mature synapses, we can now ask whether these proteins are present during neurite regeneration and synaptogenesis in vitro (Ambron, R. T., H. Den, and S. Schacher
\end{abstract}

Received October 8, 1984; Revised April 3, 1985;

Accepted April 10, 1985

\footnotetext{
${ }^{1}$ This research was supported by National Institutes of Health Grant NS 14555 and Career Development Award NS-00350 to R. T. A., National Institutes of Health Grant NS 19216 and National Science Foundation Grant 8215948 to S. S., and National Institutes of Health Grant GM 32099 which supports the mariculture facility at the Marine Biological Laboratory (Woods Hole, MA). We wish to thank R. Wooley, M. Smedman, and K. Hilten for excellent technical assistance, T. Capo and S. Perritt for rearing the animals at Woods Hole, and Dr. M. Flaster for his comments on the manuscript.

${ }^{2}$ To whom correspondence should be addressed, at Department of Anatomy and Cell Biology, College of Physicians and Surgeons, Columbia University, 630 West 168th Street, New York, NY 10032
}

(1985) J. Neurosci. 5: 2857-2865; Schacher, S., S. G. Rayport, and R. T. Ambron (1985) J. Neurosci. 5: 2851-2856).

The presynaptic terminal is structurally and functionally distinct, yet it can be great distances from the cell body which is the site of macromolecular synthesis. Two independent means of delivering proteins to the synapse have been demonstrated. Soluble proteins, including cytoskeletal components, move by slow axoplasmic flow at rates of less than $5 \mathrm{~mm} /$ day (Hoffman and Lasek, 1975). Membrane constituents, in contrast, are conveyed toward the synapse by rapid axonal transport at rates approximating $400 \mathrm{~mm} /$ day (Grafstein and Forman, 1980). We are interested in identifying proteins of the presynaptic membrane and have used rapid transport to segregate synaptic membrane constituents from proteins destined to be used elsewhere in the cell. A similar strategy has been used to study synaptic proteins of the rabbit optic pathway (Kelly et al., 1980). Proteins selectively transported to the synapse would include certain ion channels and pumps (Reichardt and Kelly, 1983), as well as components involved in maintaining interneuronal recognition and adhesion (Frazier and Glaser, 1979). Many of these constituents are known lo be glycosylated.

We have carried out our studies using $\mathrm{R} 2$, an identified cholinergic neuron of Aplysia californica. The cell body of $\mathrm{R} 2$ resides in the abdominal ganglion: its main axon courses in the right connective to ganglia in the head where it divides, sending branches into several peripheral nerves going to the body wall (Hughes and Chapple, 1967; Cobbs and Pinsker, 1978). Each branch then terminates on numerous unicellular mucus glands in the skin (Rayport et al., 1983). Using a combination of autoradiography and biochemical techniques, we found that $R 2$ is the only neuron in the abdominal ganglion with axons in the peripheral nerves going to the parapodia and middle portion of the body wall. Thus, after exposing neurons in the ganglion to $\left[{ }^{35} \mathrm{~S}\right] \mathrm{methionine}$, radiolabeled proteins transported along these peripheral nerves will all have originated from R2's cell body. Using one- and two-dimensional gel electrophoresis, 28 methioninc labeled proteins are reproducibly found to accumulate in these nerves in the isolated central nervous system. Nine of the transported constituents are glycoproteins, several of which were previously shown to be labeled after intrasomatic injection of $\left[{ }^{3} \mathrm{H}\right]$ fucose or $\left[{ }^{3} \mathrm{H}\right]-\mathrm{N}$-acetylgalactosomine (Ambron and Schwartz, 1979).

When the parapodium was left attached to its nerves, the proteins accumulated in the portion of the body wall that contains R2's target glands. We conclude, therefore, that the bulk of the proteins we have identified are en route to R2's synapses. In the preceding paper (Ambron et al., 1985), we showed that most of these proteins are present when the cell is regenerating neurites in vitro, even though no target is available for synapse formation. 


\section{Materials and Methods}

Aplysia californica weighing 50 to $125 \mathrm{gm}$, supplied by Bryan Eckert (Marine Specimens Unlimited, Pacific Palisades, CA), and animals weighing 2 to $5 \mathrm{gm}$, supplied by the mariculture facility at the Marine Biological Laboratory (Woods Hole, MA), were maintained at $15^{\circ} \mathrm{C}$ in aquaria containing Instant Ocean (Aquarium Systems, Inc., Eastlake, $\mathrm{OH}$ ). Seaweed was included as food.

Labeling of RP's proteins and glycoproteins. A portion of the central nervous system, consisting of the abdominal ganglion, attached right connective, right pleural and pedal ganglia, and attached peripheral nerves $P_{6}$ (anterior parapodial), $\mathrm{P}_{1}$ (middlc parapodial), $\mathrm{P}_{8}$ (middle pedal), and $\mathrm{P}_{9}$ (posterior pedal), was removed intact from $50-$ to $125-\mathrm{gm}$ animals and pinned in a Sylgard-coated dish containing artificial seawater (Eisenstadt et al., 1973). Nerves $P_{6} l_{0} P_{9}$ were cul just before they entered the body wall. The nomenclature for the nerves is that described by Kandel (1979). Electrophysiological experiments (Hughes and Chapple, 1967; S. G. Rayport and $K$. $\Gamma$. Ambron, unpublished results) showed that $R 2$ has axons in these nerves.

Two protocols were used to label R2's macromolecules. The first, intrasomatic injection of $\left[{ }^{3} \mathrm{H}\right]-\mathrm{L}$-fucose $(60 \mathrm{Ci} / \mathrm{mmol})$ or $\left[{ }^{3} \mathrm{H}\right]-\mathrm{N}$-acetylgalactosamine (24 Ci/mmol) (both from New England Nuclear Corp., Boston, MA) was carried out as described previously (Ambron et al., 1974a). After injection, the nervous system was maintained at $15^{\circ} \mathrm{C}$ for $50 \mathrm{hr}$. In the second, the abdominal ganglion was sequestered from the rest of the nervous system in a Vaseline well containing $0.5 \mathrm{ml}$ of Instant Ocean and 100 to $250 \mu \mathrm{Ci}$ of ${ }^{35}$ S ] methionine (Amersham Corp., Arlington Heights, IL). The outer chamber contained the rest of the nervous system (attached to the abdominal ganglion by the right connective) bathed in artificial seawater containing $5 \mathrm{~mm}$ methionine. The left portion of the nervous system, consisting of the left connective, attached pleural and pedal ganglia, and the peripheral nerves, was pinned in the outer chamber to serve as a control for the uptake of radioactivity that might have leaked from the central well. The ganglion was exposed to the labeled precursor for $5 \mathrm{hr}$ at room temperature. The central well was then washed five times with artificial seawater containing $5 \mathrm{~mm}$ methionine and the nervous system was maintained at $15^{\circ} \mathrm{C}$ for $50 \mathrm{hr}$. The bath was changed twice daily.

Before biochemical analysis, R2 was impaled and evaluated electrophysiologically to ensure that the cell was still in good condition (Ambron et al., 1974a). If it was, the cell body was removed from the ganglion. The isolated cell soma, distal half of the right connective, pleural ganglion, and each peripheral nerve were homogenized separately in sample buffer and heated at $70^{\circ} \mathrm{C}$ for $15 \mathrm{~min}$ (Ambron et al., 1985). After centrifugation to remove insoluble material, each supernatant was examined by SDS-PAGE. In some experiments the parapodium was left attached to peripheral nerves $P_{6}$ and $P_{7}$ and the body wall was attached to nerve $P_{8}$. Small (1 to $5 \mathrm{gm}$ ) animals were used to minimize the size of the tissue. After incubation, the parapodium was dissected to separate the glandular and nonglandular surfaces (Rayport et al., 1983). Both of these and the body wall were cleaned of muscle leaving the skin consisting of the epidermis, subdermis (which contains R2's target glands), and some fibrous supporting tissues. The skin was cut into segments, and the content of radiolabeled protein was analyzed by fluorography after SDS-PAGE.

Whon the distribution of labeled protcins and glycoprotein throughout the nervous system was to be determined, the labeled nervous system was frozen on the stage of a Mickel gel slicer (Brinkman Instruments, Westbury,
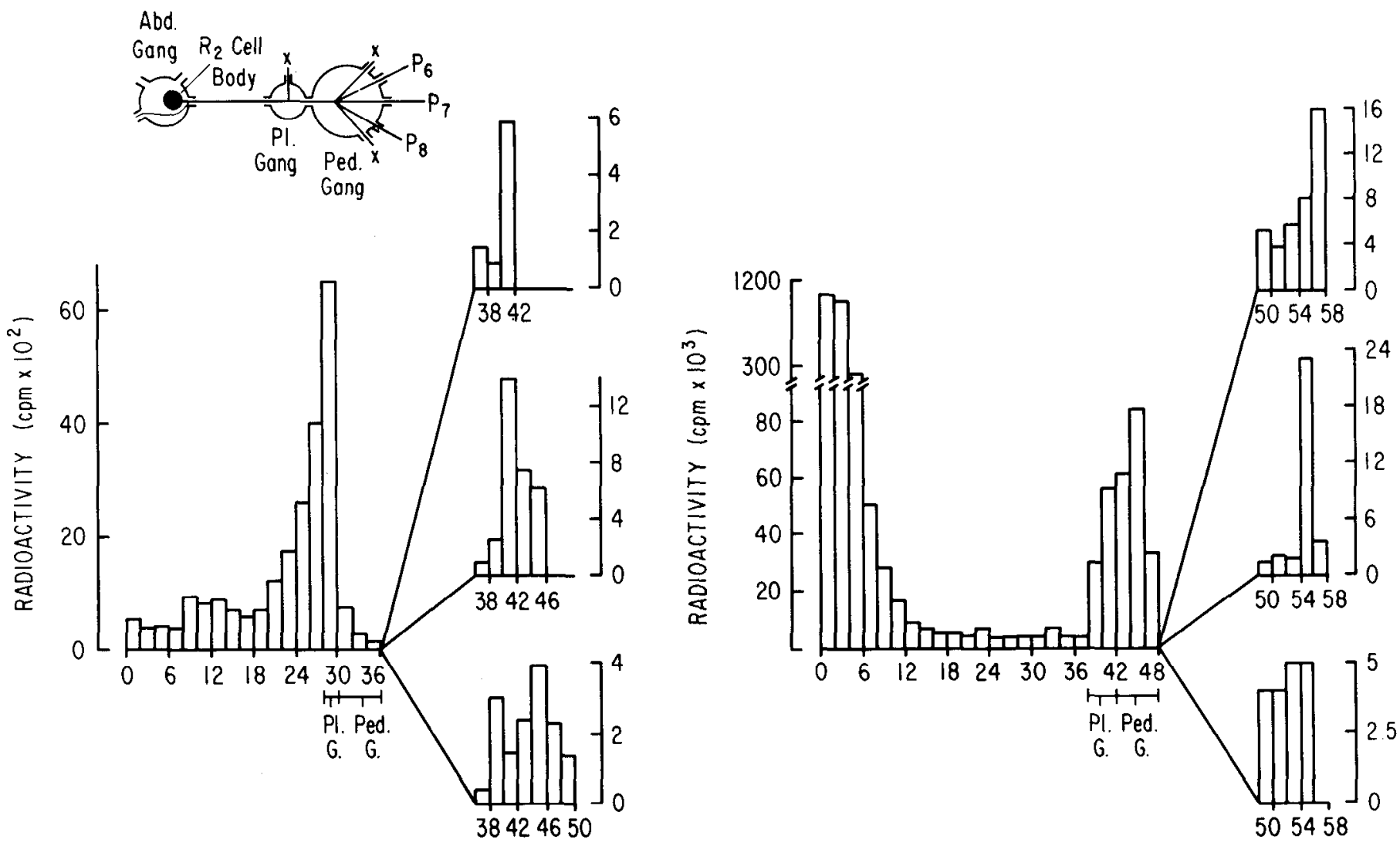

\section{DISTANCE FROM CELL BODY $(\mathrm{mm})$}

Figure 1. Distribution of radiolabeled proteins and glycoproteins in the isolated nervous system after intrasomatic injection of $\left[{ }^{3} \mathrm{H}\right]$ fucose or incubation in ${ }^{35}$ S]methionine. That portion of the nervous system shown in the diagram (upper left) was removed from the animal, and either the abdominal ganglion was incubated in $\left[{ }^{35}\right.$ S ]methionine for $5 \mathrm{hr}$ or R2 was injected with [ $\left.{ }^{3} \mathrm{H}\right]$ fucose (see "Materials and Methods"). Fifty hours later the nervous system was frozen and sectioned into sequential segments beginning with the proximal connective, and each segment was homogenized in $10 \%$ trichloroacetic acid. Left, Distribution of ${ }^{3} \mathrm{H}$-glycoproteins. Note the accumulation of ${ }^{3} \mathrm{H}$-glycoprotein at the pleural ganglion (PI. G.), where $\mathrm{R} 2$ has dendrites, and at the end of each peripheral nerve. Right, Distribution of $\left[{ }^{35}\right.$ S]methionine-labeled proteins. The large amount of radiolabeled protein in the proximal connective is moving by slow transport. Ped. G, pedal ganglion. 
$\mathrm{NY}$ ) and sectioned sequentially into 1 -mm segments. Each segment was homogenized in $10 \%$ trichloroacetic acid and the precipitated protein was collected and counted (Ambron et al., 1974a).

Polyacrylamide gel electrophoresis. Radiolabeled proteins were analyzed by one- and two-dimensional PAGE as described in the preceding paper (Ambron et al., 1985). Detection was by fluorography after exposure of the gels to Kodak X-AR film at $-80^{\circ} \mathrm{C}$ for from 1 day to 3 weeks. Fluorographs were scanned using a Joyce-Loebel microdensitometer.

Cobalt tracing of axons. Axons in the right connective were filled with cobalt so that their distribution in the pleural and pedal ganglia could be determined (Pitman et al., 1972). The central nervous system was removed from the animal and the right connective was severed approximately $1 \mathrm{~cm}$ from the pleural ganglion. The cut end was inserted into a suction electrode containing seawater which was then replaced with $2 \mathrm{M}$ cobalt acetate. After incubation at $4^{\circ} \mathrm{C}$ for 24 to $48 \mathrm{hr}$, the tissue was treated with $100 \%$ ammonium sulfide, washed, dehydrated in graded alcohols, cleared with methyl salicylate, and embedded for light microscopy. Neurites containing the cobalt appear orange against a clear background.

Extrusion of axoplasm. Axoplasm contained within the right connective was extruded at $4^{\circ} \mathrm{C}$ as described by Sherbany et al. (1984).

Autoradiography. Injected tissue was prepared for microscopy and radioautography as previously described (Thompson et al., 1976). The distribution of ${ }^{3} \mathrm{H}$-glycoprotein was determined on autoradiographs, enlarged
30,000 times, by the method of Williams (1969) as described by Ambron et al. (1981). The resulting data were compared by a $\chi^{2}$ test to ensure that the grain distribution differed significantly from random.

\section{Results}

\section{Distribution of proteins rapidly transported along R2's axon in the isolated central nervous system}

By $50 \mathrm{hr}$ after injection of $\left[{ }^{3} \mathrm{H}\right]$ fucose into R2's cell body, ${ }^{3} \mathrm{H}$ membrane glycoproteins transported along R2's axon have accumulated in the distal regions of peripheral nerves that exit from the pedal ganglion (Fig. 1, left). Since previous studies showed that radioactivity incorporated into glycoprotein after injection is restricted to the injected cell and its processes (Ambron et al., 1974a, b, 1981; Thompson et al., 1976), all of the ${ }^{3} \mathrm{H}$-glycoproteins in these nerves are constituents of R2. Not all of the peripheral nerves were labeled to the same extent, however. Nerves $P_{6}$ and $P_{7}$ to the parapodium, and nerve $\mathrm{P}_{8}$ to the middle body wall consistently had the greatest amount of radioactivity. A similar distribution was obtained when the abdominal ganglion was exposed to $\left[{ }^{35} \mathrm{~S}\right]$ methionine in a chamber separated from the rest of the nervous system (Fig. 1, right). Much
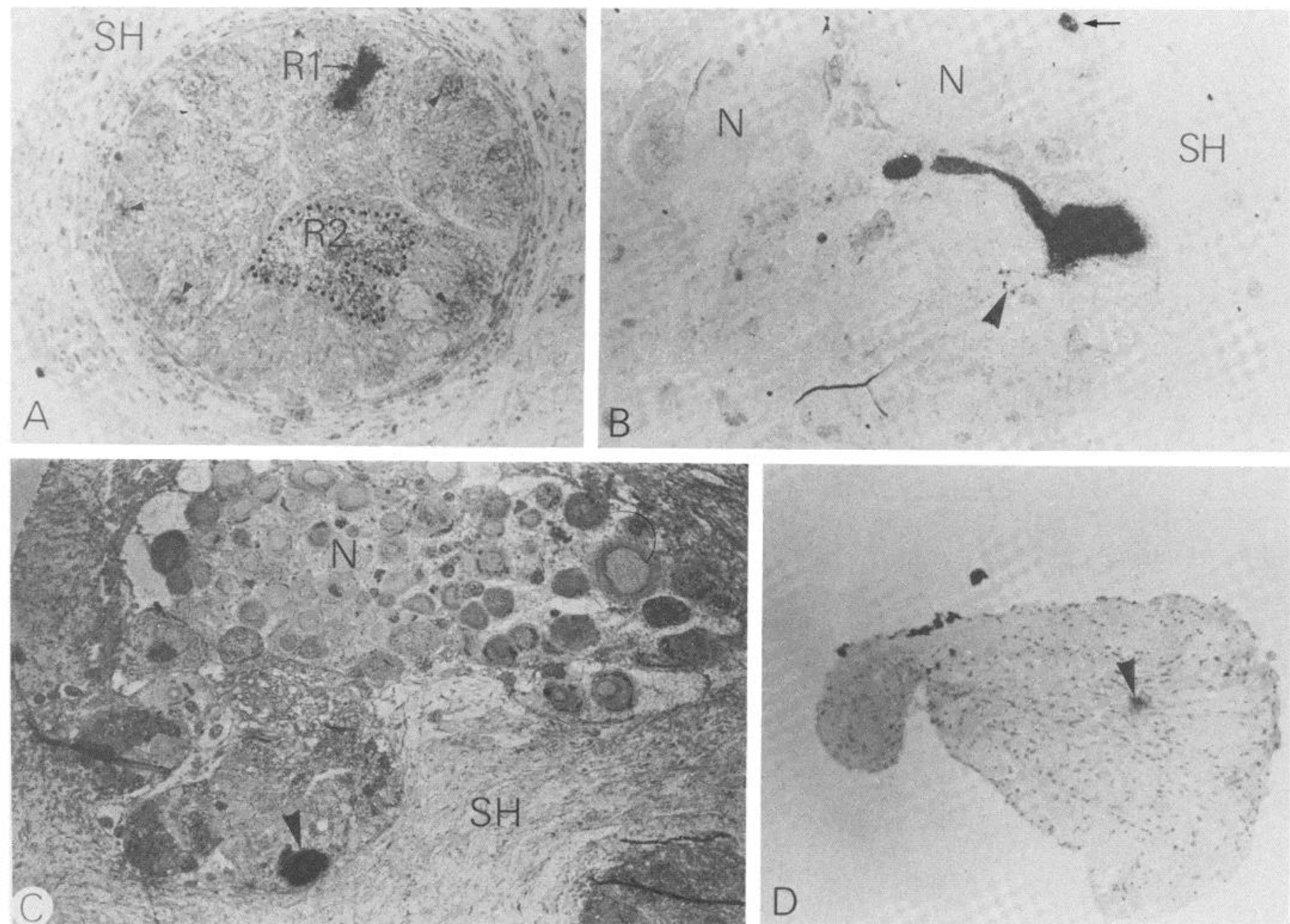

Figure 2. Light microscope autoradiographs showing the distribution of radiolabeled proteins in the isolated nervous system. Fifty hours after exposing the abdominal ganglion to a 5-hr pulse of $\left[{ }^{35} \mathrm{~S}\right]$ methionine, the tissue was fixed and processed for autoradiography. $A$, Transverse section through the distal right connective. Radioactivity is seen in the axons of R1 and R2 (outlined) and several small axons (arrowheads) of unknown identity. Most other axons are not labeled. Magnification $\times 15$. B. Part of a transverse section through the pleural ganglion. R2's axon divides: one branch exits through the pleurocerebral connective to the contralateral side; the other enters the pedal ganglion. The arrowhead points to part of R2's dendritic region. The small arrow shows a labeled axon in the sheath $(\mathrm{SH})$ that surrounds the ganglion. $\mathrm{N}$, neurons. Magnification $\times 10$. $\mathrm{C}$, Section through the pleural ganglion showing R2's labeled axon (arrowhead). Magnification $\times 5 . D$, Transverse section through one of the peripheral nerves showing a single labeled axon (arrowhead). Magnification $\times 25$. 
larger amounts of radiolabeled protein accumulated in peripheral nerves $P_{6}, P_{7}$, and $P_{8}$ after using methionine than had been achieved with injected fucose.

Although all of the neurons in the abdominal ganglion are labeled by the methionine, when the distribution of labeled axons was traced by autoradiography, R2 was the only neuron in the ganglion with axons in nerves $P_{6}$ to $P_{8}$. A typical transverse section through the distal part of the right connective is shown in Figure $2 A$. The majority of the radioactivity is associated with the large axons from $\mathrm{R} 1$ and R2. Several smaller axons, of unknown origin, are also labeled. Within the pleural ganglion, R2's axon gives off numerous dendrites (S. G. Rayport and R. T. Ambron, manuscript in preparation) that accumulate radiolabeled proteins and glycoproteins (Figs. 1 and $2 B$ ). The axon then bifurcates: one branch exits the ganglion in the cerebropleural connective to the contralateral side of the animal; the other leaves the pleural ganglion, enters the pedal ganglion, and divides, sending branches into the various peripheral nerves (Fig. 2, $C$ and $D$ ). Except for the finding that $\mathrm{R} 2$ has receptive areas in the pleural ganglion, these results are consistent with previous electrophysiological studies on the distribution of R2's axons (Hughes and Chapple, 1967). None of the other labeled axons in the right connective entered nerves $P_{6}$ to $P_{8}$. Some of the smaller axons ended in the sheath of the pleural ganglion, whereas others either exited with R2's axon through the pleurocerebral connective or their radioactivity dissipated gradually and could no longer be traced. The distribution of R1's and R2's axons can be seen clearly in Figure 3, where the axons were filled with cobalt. Branches from R2 exit through most of the nerves whereas R1's axon leaves only through nerve $P_{9}$. The path taken by $R 1$ was previously deduced by Cobbs and Pinsker (1978) based on electrophysiological recordings.

\section{Analysis of rapidly transported proteins}

The rapidly transported radiolabeled proteins from $\mathrm{R} 2$ that accumulate in the distal regions of the peripheral nerves were analyzed by SDS-PAGE. More than 30 individual nerves were examined on one-dimensional gels, and we reproducibly found 28 protein bands (Fig. 4). There was a wide variation in the amount of label in the bands from animal to animal, but consistently prominent species were found at $41,50,68,75,85$, and 110 kilodaltons (kd). All 28 polypeptide bands were present in each nerve and none of the components were preferentially routed into any one branch. Roughly 30 radiolabeled polypeptides were resolved by two-dimensional PAGE (Fig. 4 C), but this number is a minimum since several proteins did not enter the focusing gel.

In general, fewer proteins were found in the periphery than in the right connective or pleural ganglion. One labeled band in particular $\left(M_{r}=70,000\right)$ was found in the right connective but did not appear in the peripheral nerves (Fig. 4A). The material in this band accumulates in the pleural ganglion and may consist of one or more polypeptides that are deposited in R2's dendrites. Alternatively, it contains polypeptides common to the small axons that terminate in the ganglion sheath.

Our data show that glycoproteins are transported into the peripheral nerves (Fig. 1). To determine which of the transported proteins are glycosylated, we compared the composition of the peripheral nerves after labeling $\mathrm{R} 2$ with $\left[{ }^{35}\right.$ S]methionine and injecting the cell with $\left[{ }^{3} \mathrm{H}\right]$ fucose (Fig. $4 B$ ). Nine of the 28 proteins are glycoproteins. Based on previous work (Ambron et al., 1974a, b, 1981; Thompson et al., 1976), these are integral membrane constituents that are transported along R2's axon as constituents of vesicles and other organelles (see below).

We thought it reasonable that the proteins and glycoproteins that accumulate at the distal ends of the nerves were destined for R2's terminals. Evidence in support of this contention was obtained by leaving the parapodium and body wall attached to their nerves. Under these conditions, radiolabeled proteins now accumulated in the skin which contains the unicellular glands that are R2's target organ (Table I). Although it is difficult to obtain high resolution gel patterns from skin preparations due to the large proportion of unlabeled protein, in general the radiolabeled proteins were the

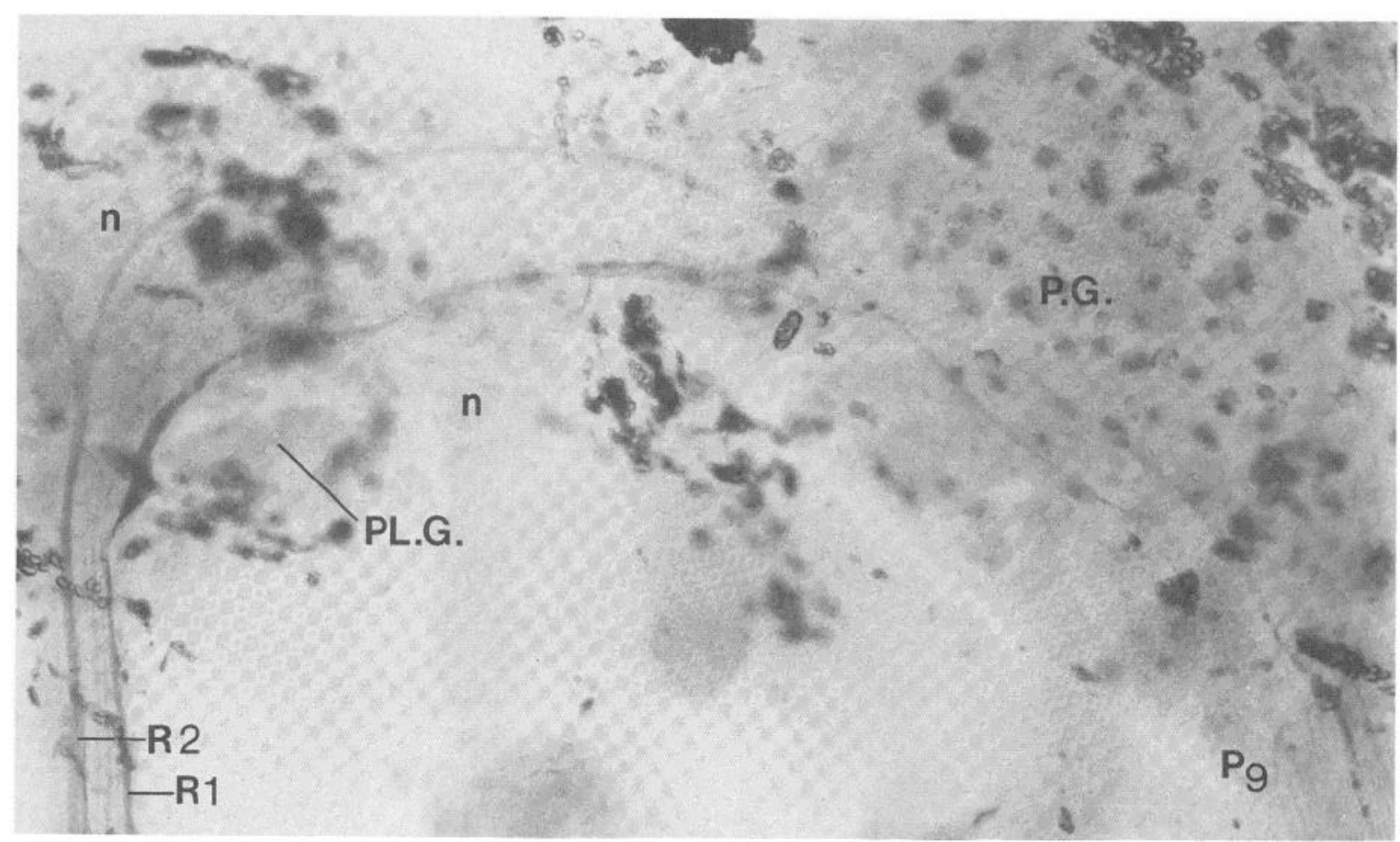

Figure 3. Cobalt tracing of R1 and R2 processes. The right connective was cut and the distal end was exposed to cobalt. Neuronal processes that transported the cobalt were visualized as described under "Materials and Methods." R2's axon, prominantly labeled in the connective, bifurcates in the pleural ganglion ( $P L$. G.) and a major branch passes through the pedal ganglion (P.G.) to exit in the posterior pedal nerve $\left(P_{9}\right)$. Other branches exit through nerves $\mathrm{P}_{6}$ to $\mathrm{P}_{8}$ but are out of the plane of focus. R1's process passes through the ganglia to accompany R2's axon in nerve $P_{9}$ : it does not have branches in the other peripheral nerves $(n)$. 

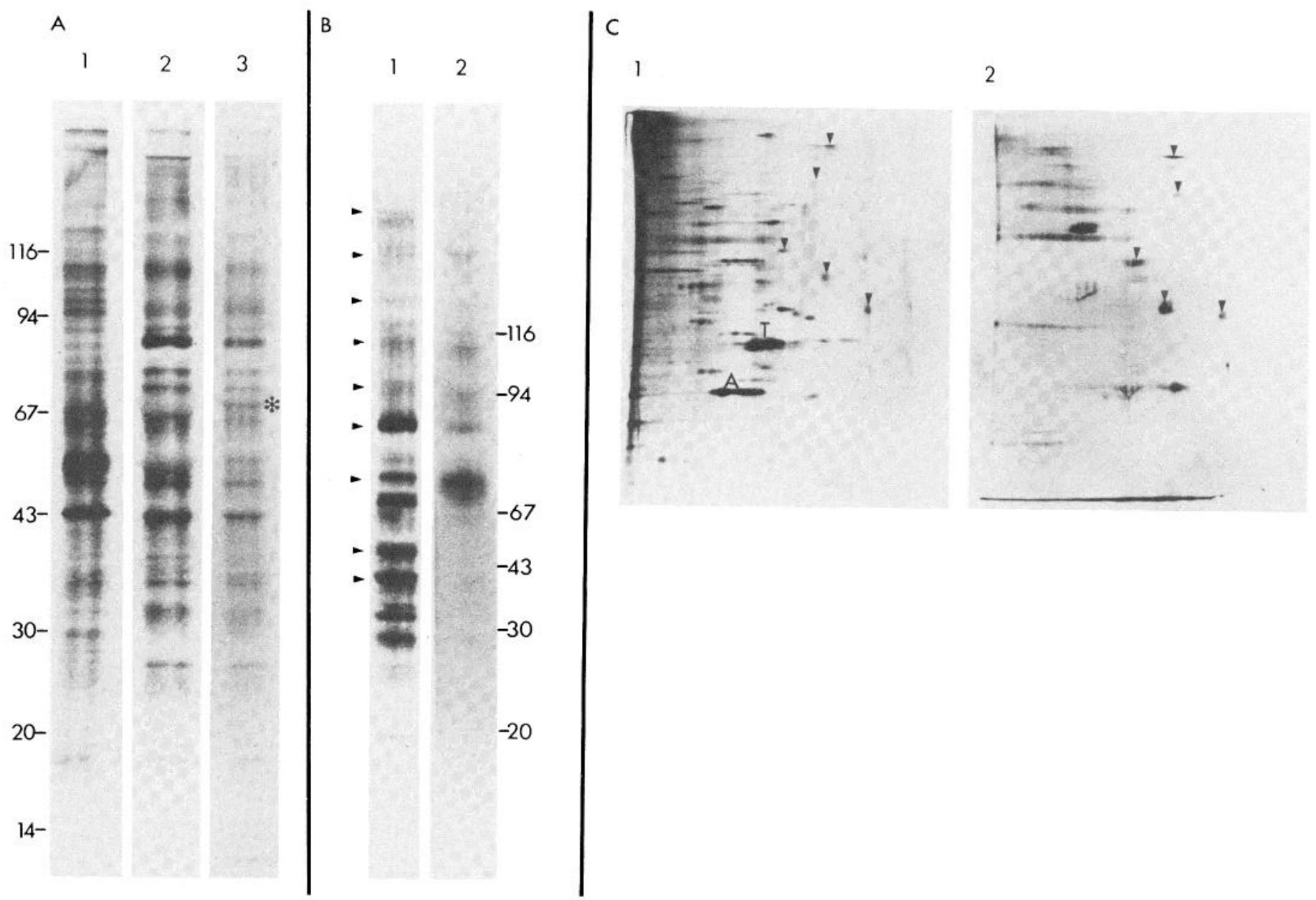

Figure 4. Fluorographs from SDS-PAGE of rapidly transported proteins and glycoproteins. A, Five to 15\% linear gradient gel of R2's cell body; (lane 1), one of the peripheral nerves (lane 2), and the distal half of the right connective (lane 3), $50 \mathrm{hr}$ after a 5 -hr pulse of [ $\left.{ }^{35} \mathrm{~S}\right]$ methionine. The asterisk denotes a protein band found in the cell body and right connective that is missing in the peripheral nerve. $B$, Lane 1: Gradient gel of peripheral nerve obtained after injection of R2 with [ $\left.{ }^{3} \mathrm{H}\right]$ fucose and incubation of the ganglion in $\left[{ }^{35} \mathrm{~S}\right]$ methionine. Each labeled band was excised and counted. Arrowheads point to bands that contained both radioactive labels. Lane 2: Gradient gel of a peripheral nerve $50 \mathrm{hr}$ after R2 was injected with [ $\left.{ }^{3} \mathrm{H}\right] \mathrm{fucose}$. C, Two-dimensional gel of R2's cell body (1) and one of the peripheral nerves, after a pulse-chase with $\left[{ }^{35} S\right]$ methionine (2). $T$, tubulin; $A$, actin. Arrowheads identify some of the more prominent polypeptides consistently found in the peripheral axon.

same as those previously found to accumulate in the peripheral nerves. There were some differences, however. Several of the labeled proteins in the skin were present in reduced amounts, and the relative migration of a $94-\mathrm{kd}$ protein may have been altered (Fig. 5).

Extrusion of proteins from the axon. Our results indicated that the transported proteins were destined for R2's synapses on the glands. Alternatively, some might be constituents of R2's axolemma. Extrusion of axoplasm has been used previously to separate axoplasm from the axolemma and surrounding glial cells (Sherbany et al., 1984). We applied this technique to determine the disposition of the proteins present in R2's axon in the distal half of the right connective $50 \mathrm{hr}$ after pulse-labeling the abdominal ganglion. By this time the main wave of rapidly transported material has passed (Fig. 1). A small proportion of the radioactivity is found in the connective, however, and it contains the same proteins found in the peripheral nerves (Fig. 4A). Under conditions where approximately $70 \%$ of the radioactivity was extruded, the pattern of labeled polypeptides from isolated axoplasm and that of the axolemma and other material remaining behind was quantitatively and qualitatively the same (not shown). Since the extruded proteins are not associated with the axolemma, they must be rapidly transported proteins that either trail behind the moving front or are exported from the cell body at times long after the 5-hr pulse.
Morphometric analysis of ${ }^{3} \mathrm{H}$-glycoproteins in R2's axon. The results of the extrusion experiments were complemented by a quantitative autoradiographic analysis of the ${ }^{3} \mathrm{H}$-glycoproteins in R2's axons. Fifty hours after intrasomatic injection of $\left[{ }^{3} \mathrm{H}\right]-\mathrm{N}$-acetylgalactosamine, the region of R2's axon proximal to the cell body and a distal region near the pleural ganglion were examined. As shown in Table II, the axolemma was labeled in the proximal but not in the distal segments. A detailed analysis of glycoproteins transported along axons of the giant cerebral neuron of Aplysia yielded similar results (Cleary and Schwartz, 1982). Taken together, these experiments indicate that the axolemma does not acquire much, if any, of its protein from the pool of rapidly transported proteins that we are studying.

\section{Discussion}

R2 has an extensive synaptic field on thousands of glands located in the skin at a considerable distance from the site of macromolecular synthesis in the cell soma. Our strategy was to use rapid axonal transport to identify those protein constituents that are transported to terminals. Included among these would be components of certain ion channels, ATPases, and a variety of receptors (Reichardt and Kelly, 1983). Glycoproteins, in particular, seem to mediate many important synaptic processes (see Mahler, 1979) including the maintenance of intercellular contacts (Edelman, 1983). Once the proteins 
destined tor R2's mature synapses have been identified, their role in synaptogenesis can be examined in vitro (Ambron et al., 1985).

The key to our approach was the discovery that $\mathrm{R} 2$ is the only neuron in the abdominal ganglion that has axons in nerves $P_{6}$ to $P_{8}$ to the periphery. From a practical perspective this meant that we could now examine the total pool of rapidly transported proteins from a single R2 neuron: in previous studies, only glycoprotein transport was examined (Ambron et al., 1981; Ambron, 1982). In

\section{TABLE ।}

Distribution of radiolabeled protein in an isolated nervous system-body wall preparation

The isolated nervous system, with the right parapodium attached to nerves $P_{6}$ and $P_{7}$ and the middle body wall attached to nerve $P_{8}$, was pinned in a dish. The abdominal ganglion was placed in a Vaseline well and was exposed to $\left[{ }^{35} \mathrm{~S}\right]$ methionine for $5 \mathrm{hr}$ followed by a 50 -hr chase. The left portion of the nervous system was pinned in the outer chamber as a control (see "Materials and Methods"). The distal half of the right connective, the pleural ganglion, and the peripheral nerves were isolated and homogenized in SDS-containing buffer, and an aliquot was removed and subjected to $10 \%$ trichloroacetic acid. The precipitated protein was then counted. The parapodium was dissected into glandular and nonglandular surfaces and the muscle layer was removed frum each, as well as from the body wall. The remaining tissue was cut into equal segments and treated as described above. The remaining SDS extracts were analyzed by SDS-PAGE (see Fig. 5). The total acidprecipitable radioactivity in the control connective, ganglion, and nerves was $328 \mathrm{cpm}$ and in the body wall, it was $223 \mathrm{cpm}$.

\begin{tabular}{lc}
\hline Distal connective & $\begin{array}{c}\text { Counts per Minute } \\
\text { in Protein }\end{array}$ \\
Pleural ganglion & 9,012 \\
Peripheral nerves & 20,412 \\
Gland layer of body wall & 1,750 \\
Glandular layer of parapodium & 6,163 \\
Nonglandular layer of parapodium & 1,563 \\
\hline
\end{tabular}

addition, by using $\left[{ }^{35}\right.$ S $]$ methionine of high specific activity, our changes of detecting even minor transported species was greatly enhanced. As shown in Figure 1, as many as 24,000 cpm accumulated at the distal end of a single peripheral nerve containing R2's axon.

Both one- and two-dimensional PAGE were used to resolve the transported proteins. On one-dimensional gels we reproducibly found 28 bands with consistently prominent species at $41,50,68$, 75, 85, and $110 \mathrm{kd}$ (Fig. 4). As expected, based on previous work (Ambron et al., 1981; Ambron, 1982), roughly one-third of the proteins are glycosylated (Fig. $4 B$ ). This is a much higher proportion

TABLE ॥

Distribution of silver grains over R2's axon $50 \mathrm{hr}$ after injection of $\left[{ }^{3} \mathrm{H}\right]-\mathrm{N}$ acetylgalactosamine ${ }^{a}$

\begin{tabular}{lcc}
\hline & \multicolumn{2}{c}{$\begin{array}{c}\text { Relative Specific } \\
\text { Activity }\end{array}$} \\
\cline { 2 - 3 } & $\begin{array}{c}\text { Proximal } \\
\text { axon }\end{array}$ & $\begin{array}{c}\text { Distal } \\
\text { axon }\end{array}$ \\
\hline Luscent vesicle & $15.8^{c}$ & $2.5^{c}$ \\
Compound vesicle & $31.0^{c}$ & $9.1^{c}$ \\
Mitochondria & $11.3^{c}$ & 0.5 \\
Smooth endoplasmic reticulum & $171^{c}$ & 0.5 \\
External membrane & $5.4^{c}$ & 0.8 \\
MVB & 3 & $11.6^{c}$ \\
\hline
\end{tabular}

${ }^{a}$ For the analysis of the proximal axon, 380 silver grains and 1250 area circles were examined. For the distal axon, 110 silver grains and 850 area circles were examined. Both grain distributions were significantly different $(\rho$ $<0.05$ ) from random as determined by a $\chi^{2}$ analysis.

${ }^{\circ}$ Ratio of the percentage of total silver grains to the percentage of total area occupied by that organelle.

'Items labeled to a greater extent than expected from a random distribution of grains. Significance $(\rho<0.05)$ was determined by a $\chi^{2}$ analysis. Axoplasm, that portion of the axon not containing a membranous organelle, was not significantly labeled.

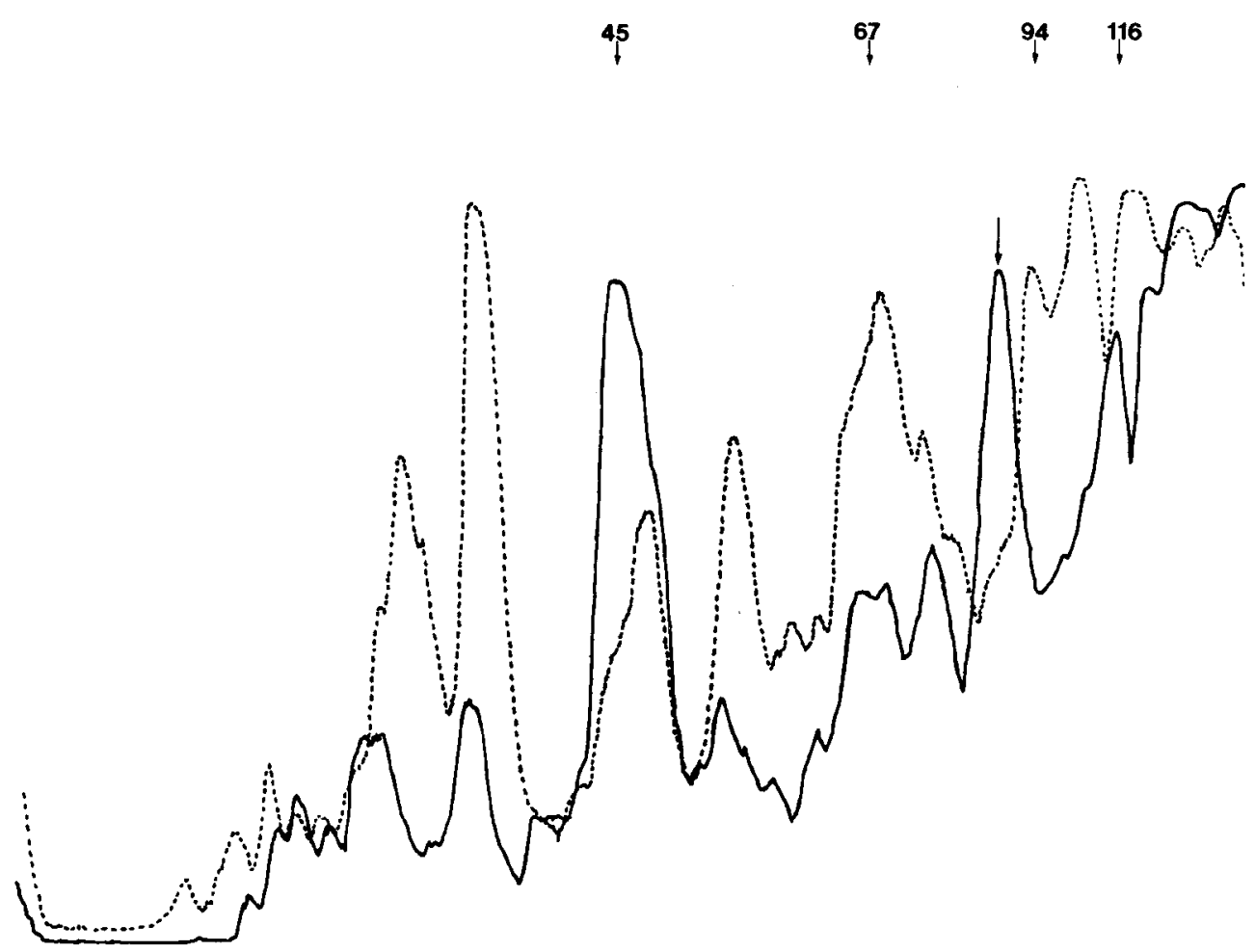

Figure 5. SDS-PAGE of rapidly transported proteins in the peripheral nerves and skin. In these experiments the body wall and parapodium were left attached to their nerves (see "Materials and Meth ods"). Fifty hours after a 3-hr pulse of $\left[{ }^{35} S\right]$ methionine, the peripheral nerves were severed from their connections and the muscle layer was removed from the body wall. The nerves (dashed line) and skin containing the glands (solid line) were analyzed by SDS-PAGE and the fluorograph was scanned by microdensitometry. Molecular weights in kd are indicated by the arrows. 
than is found in the cell body and indicates that glycoproteins are preferentially exported into the axon relative to the total protein population. It also underscores the importance of glycoproteins to the presynaptic terminal

The estimate of 28 rapidly transported proteins, determined by counting the number of bands on one-dimensional gels, appears to be reasonably accurate. Thirty spots are seen on two-dimensional gels, and there are few instances where two polypeptides have the same molecular weight but differ by isoelectric point (fig. 4C). Hence, most of the bands would contain only a single polypeptide species. A comparison between the proteins in the cell body and nerves shows that R2 exports roughly $15 \%$ of the total number of polypeptides synthesized during the 5-hr pulse (Fig. 4C). It appears, then, that R2's cell body makes a major commitment to the synthesis of proteins that are to be rapidly transported.

Several lines of evidence indicate that the transported proteins and glycoproteins are destined for R2's synapses. First, the proteins that accumulate at the distal end of the nerves would be just millimeters away from the first glandular contact had the nervous system been intact. In fact, in experiments in which we left the body wall attached to the nerves, the radiolabeled proteins accumulated in the skin containing R2's synapses. Several of the proteins were present in reduced amounts, relative to the peripheral nerve, and a 94-kd protein seemed to undergo a change in migration (Fig. 5) Similar results were obtained by Goodrum and Morell (1984), who reported that certain proteins transported to terminals of rat optic nerve turned over rapidly, whereas others were relatively stable.

Second, aside from the synapse, the other probable destination for the rapidly transported proteins would be the axolemma. However, experiments in which axoplasm was extruded from the right conneclive afler the wave of lransporled malerial had passed indicated that few, if any, of the proteins we have identified contribute to the axonal surface membrane. Autoradiographic analyses of the glycoprotein distribution supported this conclusion (Table II).

Finally, the transport kinetics for the proteins and glycoproteins fits the description of components moving toward synapses in other animals. Since we waited $50 \mathrm{hr}$ before examining the nerves, the proteins that appear in the peripheral nerves could have moved at rates between 20 and $60 \mathrm{~mm} /$ day. Extrapolating these rates onto a mammalian scale suggests that the proteins are components of what Levine and Willard (1980) have called transport groups I and II. Group I polypeptides are those that are transported at maximal rates, associated with membranous organelles, and destined for the axon and synaptic terminals. Many of the constituents of this group are glycoproteins (Mahler, 1979). Some of the glycoproteins moving along $\mathrm{R} 2$ 's axon do so in association with vesicles (Table H; see Thompson et al., 1976; Ambron et al., 1981; Cleary and Schwartz, 1982) and are candidates to be incorporated into the presynaptic surface membrane. The proteins in group \| are constituents of mitochondria, and perhaps other organelles, that move toward the synapse at an intermediate rate. $\wedge$ fast and an intermediate rate of transport have been demonstrated in R2 (Goldberg and Ambron, 1981).

An interesting issue concerns the proteins and glycoproteins found in R2's axon in the connective $50 \mathrm{hr}$ after labeling the cell. What are they doing so far behind the front of rapidly transported proteins? Proteins that apparently lag behind the moving front have also been observed in studies of the optic nerve of several mammalian species (Kelly et al., 1980; Levine and Willard, 1980; Goodrum and Morell, 1982). Earlier work on R2 had noted that fucosecontaining glycoproteins exported from the cell body were distributed along R2's axon in waves (Ambron et al., 1974b). It was subsequently shown that the glycoproteins are moving rapidly (Goldberg and Ambron, 1981), indicating that the wavelike distribution is the result of delayed release from the cell body. Our finding that labeled vesicles are present in the proximal axon $50 \mathrm{hr}$ after injection (Table II) is consistent with this idea. Goodrum and Morell (1984) recently addressed this issue using the optic system and reached a similar conclusion, namely, that there is a prolonged period after the administration of a pulse of labeled precursor during which proteins become committed to rapid transport from the cell body. The proteins we found in the connective in our experiments, then, were not trailing behind the moving front, but were released from the cell soma at a time late in the experiment.

Another point raised by our data concerns how R2's axolemma acquires its proteins. One mechanism, suggested by the results summarized in Table $\|$, would be by diffusion of macromolecules from the cell soma along the external membrane. This is probably not the only source, however. R2's proteins have a turnover rate of roughly $0.1 \% / \mathrm{hr}$ (Schwartz et al., 1971). Since we use a 5-hr pulse, the rapidly transported proteins we are studying are those with a high turnover. If the axolemmal proteins have a slow renewal time, they would be only minimally labeled by this relatively short pulse and probably would escape detection. Rapidly transported proteins contribute to the axolemma in the optic system (Goodrum and Morell, 1982).

We believe that we have identified a select group of proteins and glycoproteins that are destined for R2's synapses. Some are likely to be vesicle constituents whereas others might be associated with mitochondria and other organelles. The next step is to sort the proteins based on their distribution at the terminal. We have recently succeeded in isolating the mucus glands from the skin (Ambron et al., 1985); thus, it may be possible to fractionate R2's terminals after the arrival of the radiolabeled proteins. We have also turned to an in vitro system where R2 forms synapses under carefully controlled conditions and which is amenable to study by a variety of biochemical techniques (Ambron et al., 1985).

\section{References}

Ambron, R. T. (1982) Differences in the distribution of specific glycoproteins among the regions of a single identified neuron. Brain Res. 239: 489-505.

Ambron, R. T., and J. H. Schwartz (1979) Synthesis and regional distribution of glycoprotein and glycolipid in single neurons of Aplysia. In Complex Carbohydrates of Nervous Tissue, R. U. Margolis and R. K. Margolis, eds., pp. 269-289, Plenum Press, New York.

Ambron, R. T., J. E. Goldman, and J. H. Schwartz (19714a) Axonal transport of newly synthesized glycoproteins in a single identified neuron of Aplysia californica. J. Cell Biol. 61: 665-675.

Ambron, R. T., J. E. Goldman, E. B. Thompson, and J. H. Schwartz (1974b) Synthesis of glycoproteins in a single identified neuron of Aplysia californica. J. Cell Biol. 61: 649-664.

Ambron, R. T., A. A. Sherbany, L. J. Skolnik, and J. H. Schwartz (1981) Distribution of membrane glycoproteins among the organelles of a single identified neuron of Aplysia. I. Association of a ${ }^{3} \mathrm{H}$-glycoprotein with vesicles. Brain Res. 207: 17-32.

Ambron, R. T., H. S. Den, and S. Schacher (1985) Synaptogenesis by single identified neurons in vitro: Contribution of rapidly transported and newly synthesized proteins. J. Neurosci. 5: 2857-2865.

Cleary, L. J., and J. H. Schwartz (1982) Identification of the principle organelle carried by fast axonal transport in the giant cerebral neuron of Aplysia. Soc. Neurosci. Abstr. 8: 828 .

Cobbs, J. S., and H. M. Pinsker (1978) In vivo responses of paired mechanoreceptor neurons in Aplysia abdominal ganglion. J. Neurobiol. 9: 121141.

Edelman, G. M. (1983) Cell adhesion molecules. Science 219: 450-457.

EIsenstadt, M., J. E. Goldman, E. R. Kandel, H. Koike, J. Koester, and J. H. Schwartz (1973) Intrasomatic injection of radioactive precursors for studying transmitter synthesis in identified neurons of Aplysia californica. Proc. Natl. Acad. Sci. U. S. A. 70: 3371-3375.

Frazier, W., and L. Glaser (1979) Surface components and cell recognition. Annu. Rev. Biochem. 48: 491-523.

Goldberg, D. J., and R. T. Ambron (1981) Two rates of fast axonal transport of ${ }^{3} \mathrm{H}$-glycoprotein in an identified invertebrate neuron. Brain Res. 229: 445-455.

Goodrum, J. F., and P. Morell (1982) Axonal transport and metabolic turnover of glycoproteins in the rat optic pathway. J. Neurochem. 38: 696-704

Goodrum, J. F., and P. Morell (1984) Analysis of the apparent biphasic axonal transport kinetics of fucosylated glycoproteins. J. Neurosci. 4: 1830-1839. 
Grafstein, B., and D. S. Forman (1980) Intracellular transport in neurons. Physiol. Rev. 60: 1167-1283.

Hoffman, P. N., and R. J. Lasek (1975) The slow component of axonal transport. Identification of major structural polypeptides of the axon and their generality among mammalian neurons. J. Cell Biol. 66: 351-366.

Hughes, E. M., and W. D. Chapple (1967) The organization of nervous systems. In Invertebrate Nervous Systems. Their significance for Mammalian Neurophysiology, C. A. G. Wiersma, ed., pp. 000-000, University of Chicago Press, Chicago.

Kandel, E. R. (1979) Behavioral Biology of Aplysia, p. 125, W. H. Freeman and Co., New York.

Kelly, A. S., J. A. Wagner, and R. B. Kelly (1980) Properties of individual nerve terminal proteins identified by two-dimensional gel electrophoresis. Brain Res. 185: 192-197.

Levine, J., and M. Willard (1980) The composition and organization of axonally transported proteins in the retinal ganglion cells of the guinea pig. Brain Res. 194: 137-154.

Mahler, H. R. (1979) Glycoproteins of the synapse. In Complex Carbohydrates of Nervous Tissue, R. U. Margolis and R. K. Margolis, eds., pp. 165-184, Plenum Press, New York.

Pitman, R. N., C. D. Tweedle, and M. J. Cohen (1972) Branching of central neurons: Intracellular cobalt injection for light and electron microscopy. Science 176: 412-415

Rayport, S. G., R. T. Ambron, and J. Babiarz (1983) Identified neurons R2 and LP1, control mucus release in Aplysia. J. Neurophysiol. 49: 864-876.

Reichardt, L. F., and R. B. Kelly (1983) A molecular description for nerve terminal function. Annu. Rev. Biochem. 52: 871-926

Schacher, S., S. G. Rayport, and R. T. Ambron (1985) Giant Aplysia neuron $\mathrm{R} 2$ reliably forms strong chemical connections in vitro. J. Neurosci. 5 : 2851-2856

Schwartz, J. H., V. F. Castellucci, and E. R. Kandel (1971) Functioning of identified neurons and synapses in abdominal ganglion of Aplysia in absence of protein synthesis. J. Neurophysiol. 34: 939-953.

Sherbany, A. A., R. T. Ambron, and J. H. Schwartz (1984) Characterization of glycolipids synthesized in an identified neuron of Aplysia californica. J. Neurosci. 4: 1875-1883.

Thompson, E. B., J. H. Schwartz, and E. R. Kandel (1976) A radioautographic analysis in the light and electron microscope of identified Aplysia neurons and their processes after intrasomatic injection of $\mathrm{L}-\left[{ }^{3} \mathrm{H}\right]$-fucose. Brain Res. 112: $251-281$.

Williams, M. A. (1969) The assessment of electron microscopic autoradiographs. Adv. Opt. Electron Microsc. 3: 219-272. 